\title{
Mangalda Pişirilmiş Sebzelerin Polisiklik Aromatik Hidrokarbon İçeriği
}

\author{
Emel ÖZ ${ }^{* 1}$, Adem SAVAŞ ${ }^{1}$, Elif EKİZ ${ }^{1}$, Fatih ÖZ ${ }^{1}$
}

\section{öz}

Araştırmada mangalda pişirilmiş sebzelerin (domates, sarımsak, soğan, patlıcan, sivri biber, yeşil biber, kapya biber) polisiklik aromatik hidrokarbon (PAH) içeriğinin belirlenmesi amaçlanmıştır. PAH bileşikleri QuEChERS yöntemi ile ekstrakte edilmiş ve PAH seviyesi HPLC-FLD ile analiz edilmiştir. $\mathrm{BaP}$ seviyesinin patlıcan ve sivri biber örneklerinde sırasıyla $1.5 \mathrm{ve} 2.48 \mathrm{ng} / \mathrm{g}$ düzeyinde olduğu belirlenmiştir. Sarımsak ve yeşil biber örneklerinde BaP miktarının kantitatif ölçme sınırının altında kaldığı gözlenmiştir. BaA $(0.33-2.30 \mathrm{ng} / \mathrm{g})$ ve Chry $(\mathrm{nq}-3.69 \mathrm{ng} / \mathrm{g})$ tüm sebzelerde tespit edilmiştir. Domates, soğan ve kapya biberin diğer sebzelere kıyasla daha düşük seviyelerde PAH içerdiği, patlıcan ve sivri biberin ise incelenen tüm genotoksik PAH bileşiklerini içerdiği belirlenmiştir.

Anahtar Kelimeler: Sebze, mangal, polisiklik aromatik hidrokarbon, QuEChERS, HPLC-FLD

\section{Polycyclic Aromatic Hydrocarbon Content of Barbecued Vegetables} \begin{abstract}
Herein, it was aimed to determine the polycyclic aromatic hydrocarbon (PAH) content of barbecued vegetables (tomato, garlic, onion, eggplant, green pepper, chili pepper, capia pepper). PAH compounds were extracted by QuEChERS method and PAH level was analyzed by HPLCFLD. BaP level was 1.5 and $2.48 \mathrm{ng} / \mathrm{g}$ in eggplant and chili pepper, respectively. $\mathrm{BaP}$ in garlic and green pepper was below the LOQ value. BaA $(0.33-2.30 \mathrm{ng} / \mathrm{g})$ and Chry $(\mathrm{nq}-3.69 \mathrm{ng} / \mathrm{g})$ were detected in all vegetables. Tomato, onion and capia pepper had lower PAH contents compared to other vegetables, while eggplant and chili pepper contained all genotoxic PAH compounds.
\end{abstract}

Keywords: Vegetable, barbecuing, polycyclic aromatic hydrocarbon, QuEChERS, HPLC-FLD

ORCID ID (Yazar sırasına göre)

0000-0003-3766-2713, 0000-0002-4365-1482, 0000-0002-5557-4226, 0000-0002-5557-4226

Yayın Kuruluna Geliş Tarihi: 31.12.2020

Kabul Tarihi: 01.02.2021

${ }^{1}$ Gıda Mühendisliği Bölümü, Ziraat Fakültesi, Atatürk Üniversitesi, 25240, Erzurum, Türkiye

*E-posta: emel.oz@atauni.edu.tr 


\section{Mangalda Pişirilmiş Sebzelerin Polisiklik Aromatik Hidrokarbon İçeriği}

\section{Giriş}

Polisiklik aromatik hidrokarbon (PAH)'lar organik materyallerin tam yanmamasi veya pirolizi yoluyla oluşan, iki veya daha fazla kaynaşmış benzen halkası içeren organik bileşikler olarak tanımlanmakta ve yaygın çevresel kirleticiler olarak kabul edilmektedir (Sun ve ark., 2019). Epidemiyolojik çalışmalar bu bileşiklerin hücresel membranın normal işleyişine ve enzim sistemine müdahale etmek suretiyle organizmaları etkileyebildiğini göstermiştir (Bogdanovic ve ark., 2019). Storelli ve ark. (2003), PAH'ların DNA'ya bağlanmak suretiyle DNA replikasyonunda hatalara yol açabilecek eklentiler oluşturarak karsinojen süreci başlatan mutasyonlara neden olduğunu bildirmişlerdir. Mutajenik ve/veya karsinojenik özellikleri olan bu bileşiklerden, beş veya daha fazla kaynaşmış benzen halkası içeren ve ağır PAH'lar olarak adlandırılanların, iki-dört kaynaşmış benzen halkası içeren ve hafif PAH'lar olarak adlandırılanlara göre daha stabil ve toksik oldukları bildirilmiştir (PlazaBolanos ve ark., 2010). Bu bağlamda, günümüze dek 660'a yakın PAH bileşiği tanımlanmış olsa da, bunlardan sadece 16 tanesinin öncelikli kontaminant olduğu rapor edilmiştir (Oz, 2020a). Uluslararası Kanser Araştırma Ajansı (IARC) ise bu 16 öncelikli kontaminant arasından benzo(a)piren (BaP)'i Grup 1 (bilinen insan karsinojeni) ve Benzo[a]antrasen (BaA), Krisen (Chr) ve Benzo[b]floranten (BbF)' $i$ ise Grup 2B (muhtemel karsinojen) olarak sinıflandırmıştır (IARC, 2010). Günümüzde $\mathrm{BaP}$ ile $\mathrm{BaP}, \mathrm{BaA}$, Chr ve BbF'nin toplamın ifade eden PAH4 seviyeleri, PAH'ların karsinojenik gücünün bir göstergesi olarak kabul edilmekte ve gidalardaki PAH oluşumunun değerlendirilmesinde indikatör olarak kullanılmaktadırlar (Rose ve ark., 2015).

PAH'lar volkanik patlamalar, orman yangınları, endüstriyel baca gazları, araba egzozları gibi pek çok kaynakta bulunabilse de insanlar için en önemli PAH kaynağının gıdalar olduğu (Li ve ark., 2019) ve gidaların PAH kirliliğinin yaklaşık \%88-98'inden sorumlu olduğu bildirilmektedir (Singh ve ark., 2020). Bu çevresel kirleticiler, gidalara kirli su, hava ve topraktan bulaşabilmekle birlikte, tütsüleme, kızartma, 1zgara ve mangal gibi bazı işleme prosesleri de gidalarda PAH oluşumuna sebep olabilmektedir (Martorell ve ark., 2010). Gıdaların 1sıl işleme tabi tutulması esnasında PAH'ların oluşum mekanizması tam olarak bilinememekle birlikte (Lee ve ark., 2016), genel olarak kabul görmüş üç teori bulunmaktadır. $\mathrm{Bu}$ teorilerden birincisi, gida bünyesinde bulunan organik bileşenlerin $200{ }^{\circ} \mathrm{C}$ veya üzerindeki sicaklıklarda pirolizi, ikincisi gıda bünyesinde bulunan yağın 1sı kaynağına damlaması ve üçüncüsü de 1 s1 kaynağ1 olarak kullanılan yakıtın tam yanmamasıdır (Singh ve ark., 2020).

Mangalda pişirme, ülkemizde sıklıkla tercih edilen popüler bir pişirme tekniğidir. Bununla birlikte, gida ve pişirme kaynağı arasında direkt temas olması PAH oluşumu ve konsantrasyonu bakımından bu yöntemin riskini artırmaktadır (Oz, 2020b). Kazerouni ve ark. (2001) gidaların doğrudan duman veya pişirme kaynağ temas ettiği pişirme yöntemlerinde oluşan $\mathrm{PAH}$ konsantrasyonunun indirekt pişirme yöntemlerine kıyasla daha yüksek olduğunu bildirmişlerdir. Çeşitli pişirme tekniklerinin gıdalardaki PAH oluşum düzeyi üzerine etkisinin incelendiği pek çok araştırma bulunmakla birlikte bu araştırmaların çoğu et ve et ürünlerine yöneliktir. Pişirilmiş sebzelerde PAH seviyesinin incelendiği sadece birkaç çalışma (Alomirah ve ark., 2011; Akpambang ve ark., 2015; Cheng ve ark., 2019) bulunmaktadır. Pişirilerek tüketilen sebzelerin de insanlardaki PAH maruziyetine katk1 sağlayabileceği düşünüldüğünde bu kapsamda yapılacak çalışmalara ihtiyaç olduğu açıktır. Bu nedenle mevcut bu araştırmada mangalda pişirilmiş bazı sebzelerin (domates, sarımsak, soğan, patlıcan, sivri biber, yeşil biber ve kapya biber) pişirilmesi esnasında oluşan $\mathrm{PAH}$ seviyelerinin incelenmesi amaçlanmıştır.

\section{Materyal ve Yöntem \\ Materyal}

Sebze [domates $(\sim 1 \mathrm{~kg})$, sarımsak $(\sim 500 \mathrm{~g})$, soğan $(\sim 1 \mathrm{~kg})$, patlican $(\sim 1 \mathrm{~kg})$, sivri biber $(\sim 500 \mathrm{~g})$, yeşil biber $(\sim 500 \mathrm{~g})$ ve kapya biber $(\sim 1 \mathrm{~kg})]$ örnekleri Erzurum'daki yerel bir sebze satıcısından temin edilmiş ve pişirme öncesi su 


\section{Mangalda Pişirilmiş Sebzelerin Polisiklik Aromatik Hidrokarbon İçeriği}

ile yıkanarak temizlenmiştir. Araştırmada her bir tekerrür için, her bir sebze grubundan 4 adet kullanılmıştır.

\section{Kimyasallar}

Araştırmada HPLC-grade kalitesinde kimyasal ve çözeltiler kullanılmıştır. Ayrıca HPLC-grade çözücüler hariç olmak üzere tüm çözeltiler 0.45 $\mu$ m'lik filtreden (Milex ${ }^{\circledR}$, Massachusetts, USA) süzüldükten sonra kullanılmıştır. Q-sep Q150 QuEChERS ekstraksiyon tuzları (6 g $\mathrm{MgSO}_{4}$, $1.5 \mathrm{~g}$ NaOAc, $50 \mathrm{~mL})$ ve Q-sep Q351 QuEChERS dSPE (1200 mg $\mathrm{MgSO}_{4}, 400 \mathrm{mg}$ PSA, 400 mg C18, $15 \mathrm{~mL}$ ) Restek (Bellefonte, Amerika Birleşik Devletleri)'den satın alınmıştır. Benzo[a]antrasen (BaA), Krisen (Chr), Benzo[b]floranten (BbF), Benzo[k]floranten (BkF), Benzo[a]piren (BaP), Indeno[1,2,3-cd]piren (IncdP), Benzo[g,h,i]perilen (BghiP), ve Dibenzo[a,h]antrasen (DahA) bireysel PAH'larını içeren PAH standart karışımı ise Supelco (Bellefonte, Amerika Birleşik Devletleri)'dan temin edilmiştir. Stok ve seyreltilmiş $\quad \mathrm{PAH}$ standartlarının hazırlanmasında asetonitril kullanılmıştır $(\mathrm{Oz}$ ve ark., 2020).

\section{Pişirme Koşulları}

Sebze örneklerinin mangalda pişirilmesinde tel mangal (genişlik, uzunluk ve yükseklik: $25 \times$ $40 \times 7 \mathrm{~cm})$ kullanılmıştır. Yıkanmış sebze örnekleri kabuklu olarak pişirilmiştir. Pişirme işleminde tamamen tutuşturulmuş ve dengeli 1sıtma için mangal yüzeyine eşit yayılmış odun kömürü kullanılmıştır. Mangal yüzey sıcaklığı $\left(200{ }^{\circ} \mathrm{C}\right.$ ) dijital bir termokapl (Testo 926, Almanya) ile ölçülmüştür. Sebze örnekleri toplam pişirme süresinin (8 dakika) yarısında ters çevrilmiş ve PAH analizi kabuğu soyulmuş örneklerde gerçekleştirilmiştir.

\section{Polisiklik Aromatik Hidrokarbonların Analizi \\ PAH'ların ekstraksiyonunda QuEChERS ekstraksiyon yöntemi kullanılmıştır ( $\mathrm{Oz}$ ve ark., 2020). Bu amaçla, $5 \mathrm{~g}$ sebze örneği ve $10 \mathrm{~mL}$ ultra saf su 1 dakika süreyle vortekslenmiştir. Üzerine ekstraksiyon çözücüsü olarak, \%1 asetik asit içeren $10 \mathrm{~mL}$ asetonitril eklenip 2 dakika daha vortekslenmiştir. $\mathrm{Bu}$ işlemin}

ardından, karışımın üzerine $6 \mathrm{~g} \mathrm{MgSO}_{4}$ ve $1.5 \mathrm{~g}$ $\mathrm{NaOAc}$ içeren Q150 QuEChERS ekstraksiyon tuzu eklenerek 1 dakika daha vortekslenmiştir. Ardından karışımı içeren santrifüj tüpü 4000 rpm'de 5 dakika santrifüj edilmiştir. Üst katman $1200 \mathrm{mg} \mathrm{MgS0}{ }_{4}, 400 \mathrm{mg}$ PSA ve $400 \mathrm{mg} \mathrm{C18}$ içeren Q351 QuEChERS dSPE tüpüne aktarılıp 1 dakika boyunca vortekslenmiştir. Ardından tüp 4000 rpm'de 5 dakika santrifüj edilmiştir. Son aşamada üst tabakanın bir kısmı 0.45 $\mu \mathrm{m}$ 'lik bir filtreden süzüldükten sonra bir HPLC vialine transfer edilmiştir.

PAH bileşiklerinin tanımlanmasında ve miktarının belirlenmesinde FLD dedektörlü HPLC (Thermo Ultimate 3000; Thermo Scientific) ve $3 \mu \mathrm{m}$ partükül büyüklügünde (150 mm x $2.1 \mathrm{~mm}$, Hichrom, Birleşik Krallık) HypersilTM Green PAH kolonu kullanılmıştır. Mobil faz A ve B olarak sirasiyla deiyonize su ve asetonitril kullanılmıştır. Akış hızı 0.6 $\mathrm{mL} /$ dak ve gradyan program, $0-22$ dakika $\% 50$ $\mathrm{B}$ ve $22-24$ dakika $\% 100 \mathrm{~B}$ şeklindeydi $(\mathrm{Oz}$ ve Yuzer, 2016).

Metot validasyonunda, tek laboratuvar doğrulamasına uygun olarak, LOD (limits of detection), LOQ (limits of quantification), doğrusallık $\left(\mathrm{R}^{2}\right)$ ve geri kazanım parametreleri değerlendirilmiştir. LOD ve LOQ değerleri sirasıyla 3 ve 10'luk sinyal/gürültü oran1 dikkate alınarak hesaplanmıştır. Doğrusallık, regresyon analizi ile değerlendirilirken; bireysel PAH bileşiklerinin geri kazanım oranlarının belirlenmesinde standart ilave metodu kullanılmıştır. PAH bileşiklerinin tanımlanmasında PAH standartlarının alıkonma sürelerinden yararlanılmış, miktar belirlenmesinde ise external kalibrasyon eğrisi metodu kullanılmıştır. Kalibrasyon eğrisinin çizilmesinde konsantrasyonu $1-100 \quad \mathrm{ng} / \mathrm{g}$ arasında değişen 6 farklı standart konsantrasyonu kullanılmıştır (Oz, 2020b).

\section{İstatistiksel Analiz}

Araştırma, tam şansa bağlı bloklar deneme desenine göre iki tekerrürlü olarak kurulmuş ve her bir tekerrür iki paralelli olarak çalışılmıştır. Sonuçlar ortalama \pm standart sapma olarak ifade edilmiştir. Ayrıca örnekler arasındaki benzerlik ve farklılıkların tanımlanmasını kolaylaştırmak 
için tüm verilere temel bileşen analizi (PCA) uygulanmıştır (SIMCA-P + 14.1, UMETRICS, İsveç).

\section{Bulgular ve Tartışma}

Pişmiş Sebzelerin Polisiklik Aromatik Hidrokarbon İcerikleri

Araştırmada kullanılan PAH standart karışımına ait LOD ve LOQ değerleri ile geri kazanım oranları Tablo 1'de sunulmuştur. Buna göre, LOD ve LOQ değerleri sirasılyla 0.027 $0.125 \mathrm{ng} / \mathrm{g}$ ile $0.089-0.413 \mathrm{ng} / \mathrm{g}$ arasında değişmiş ve PAH bileşiklerinin geri kazanım oranları \% 70.14-85.10 arasında olmuştur. Avrupa Komisyonu Yönetmeliği'nde (No 836/2011) PAH'lar için geri kazanım oranlarının \% 50-120 arasında olmas1 gerektiği bildirilmiştir. Mevcut araştırmada incelenen tüm PAH standart eğrilerinin regresyon katsayılarının $\left(\mathrm{R}^{2}\right)$ 0.999'un üzerinde olduğu belirlenmiştir. Analiz güvenilirliğini ilgilendiren bu sonuçlar EC (2011) tarafından bildirilen performans kriterleri ile uyum içerisindedir. Ayrıca mevcut araştırmada incelenen bu metot performans kriterleri, bu kapsamda yapılan diğer araştırmalar ile karşılaştırılabilir niteliktedir (Cheng ve ark., 2019; Lee ve ark., 2019; Oz ve ark., 2020). Şekil 1'de $10 \mathrm{ng} / \mathrm{g}$ konsantrasyondaki PAH standardına ait HPLC kromatogramı gösterilmiştir.

Tablo 1. PAH standart karışımında yer alan bireysel PAH bileşiklerinin LOD ve LOQ değerleri ile geri kazanım oranları

\begin{tabular}{|c|c|c|c|c|c|}
\hline PAH bileşiği & Molekül yapısı & $\begin{array}{c}\text { Kimyasal } \\
\text { formül }\end{array}$ & $\begin{array}{l}\text { LOD } \\
\text { (ng/g) }\end{array}$ & $\begin{array}{c}\text { LOQ } \\
\text { (ng/g) }\end{array}$ & $\begin{array}{c}\text { Geri kazanım } \\
(\%)\end{array}$ \\
\hline $\mathrm{BaA}$ & & $\mathrm{C}_{18} \mathrm{H}_{12}$ & 0.027 & 0.089 & 85.10 \\
\hline Chry & & $\mathrm{C}_{18} \mathrm{H}_{12}$ & 0.034 & 0.112 & 79.25 \\
\hline $\mathrm{BbF}$ & & $\mathrm{C}_{20} \mathrm{H}_{12}$ & 0.086 & 0.284 & 78.77 \\
\hline $\mathrm{BkF}$ & & $\mathrm{C}_{20} \mathrm{H}_{12}$ & 0.065 & 0.215 & 83.76 \\
\hline $\mathrm{BaP}$ & & $\mathrm{C}_{20} \mathrm{H}_{12}$ & 0.069 & 0.228 & 81.10 \\
\hline DahA & & $\mathrm{C}_{22} \mathrm{H}_{14}$ & 0.083 & 0.274 & 75.38 \\
\hline BghiP & & $\mathrm{C}_{22} \mathrm{H}_{12}$ & 0.125 & 0.413 & 82.89 \\
\hline IncdP & & $\mathrm{C}_{22} \mathrm{H}_{12}$ & 0.113 & 0.373 & 70.14 \\
\hline
\end{tabular}




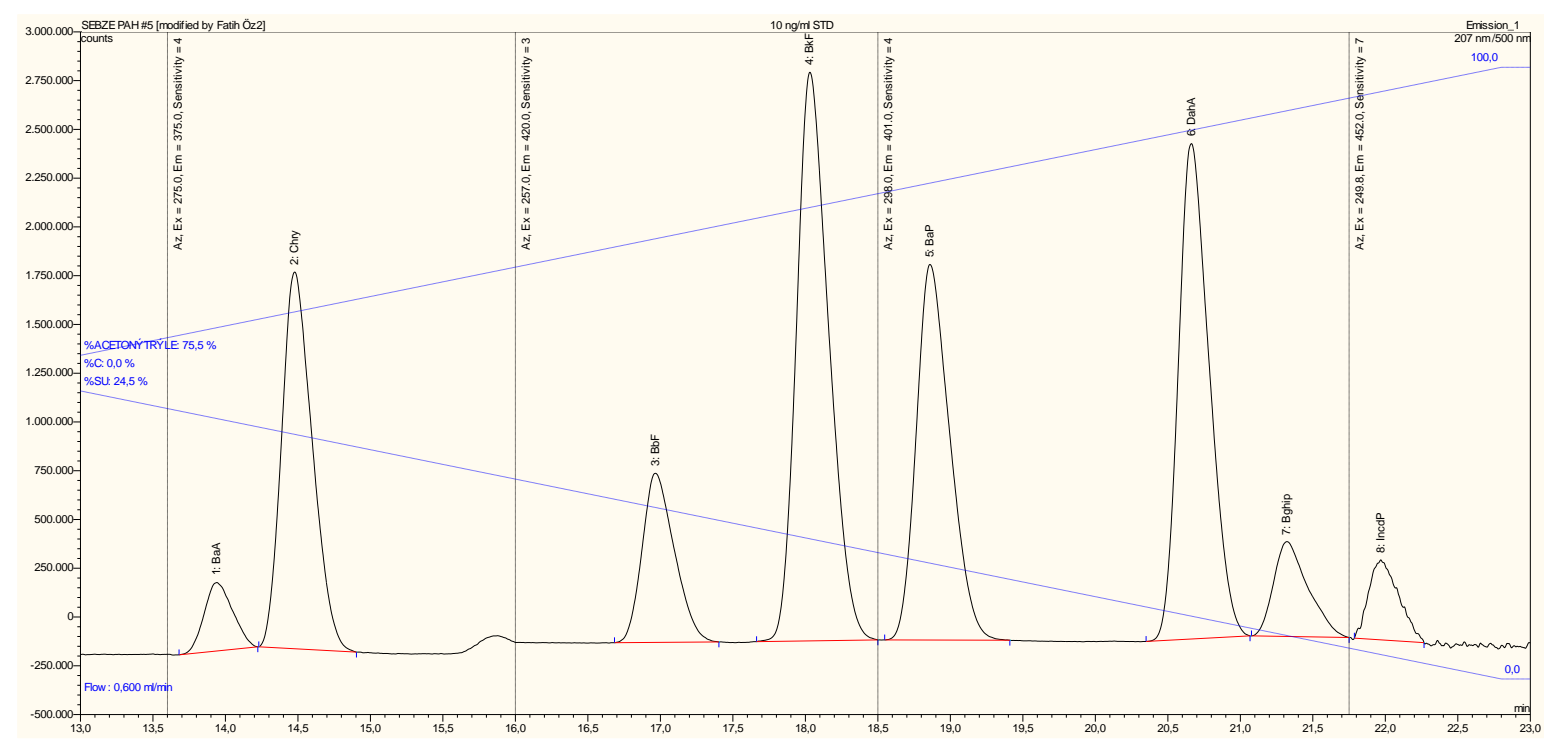

Şekil 1. $10 \mathrm{ng} / \mathrm{g}$ konsantrasyondaki PAH standardına ait HPLC kromatogramı (Pik no 1: BaA, 2: Chry, 3: BbF, 4: BkF, 5: BaP, 6: DahA, 7: BghiP, 8: IncdP)

Mangalda pişirilmiş sebze örneklerinin PAH içeriklerine ait sonuçlar Tablo 2'de sunulmustur. BaA, Chry, BbF, BkF, BaP ve BghiP'in sebzelerde PAH karsinojenitesine katk1 sağlayan en önemli bireysel PAH bileşikleri olduğu rapor edilmiştir (Wang ve ark., 2016; Cheng ve ark., 2019). Bu bağlamda mevcut araştırmada incelenen 8 genotoksik PAH bileşiği arasında sebze örneklerinde en yaygın bulunanların $\mathrm{BaA}$ ve Chry olduğu gözlenmiştir. İncelenen tüm pişmiş sebzelerde, değişen seviyede $\mathrm{BaA}(0.33-2.30 \mathrm{ng} / \mathrm{g})$ ve Chry (nq-3.69 ng/g) tespit edilmiştir. Ayrıca BbF (nq-1.85 ng/g) sarımsak, patlican ve sivri biber örneklerinde; BkF (nq-0.86 ng/g) yeşil biber, patlican ve sivri biber örneklerinde ve BghiP ise (nq-1.57 ng/g) sarımsak, patlican, sivri biber ve yeşil biber örneklerinde tespit edilmiştir. Uluslararası Kanser Araştırma Ajansı tarafından bilinen insan karsinojenleri kategorisinde siniflandirılan (IARC, 2010) ve gidalardaki PAH riskinin değerlendirilmesinde bir indikatör olarak kullanılan $\mathrm{BaP}$ ise sadece patlican ve sivri biber örneklerinde sirasiyla 1.50 ve 2.48 $\mathrm{ng} / \mathrm{g}$ seviyelerinde tespit edilmiştir. Sarımsak ve yeşil biber örneklerinin $\mathrm{BaP}$ içeriği ise kantitatif ölçme sınırın altında kalmıştır. Alomirah ve ark. (2011) piyasadan temin ettikleri közlenmiş domates, soğan ve kırmızı biber örneklerinde
$\mathrm{BaP}$ içeriğinin nd-3.43 ng/g arasında olduğunu bildirmişlerdir. Akpambang ve ark. (2015) ise Nijerya'ya özgü kavrulmuş bir sebzede BaP seviyesinin 0.3-0.6 ng/g arasında olduğunu bildirmiştir. Diğer taraftan mevcut araştırmada BaP'in tespit edilmediği domates, soğan ve kapya biber örneklerinde değişen seviyelerde diğer genotoksik PAH bileşiklerinin tespit edilmesi, gidalardaki PAH riskinin değerlendirilmesinde sadece BaP'nin değil PAH4 ve PAH8 seviyelerinin de önemli olduğu fikrini desteklemektedir.

Mangalda pişirilmiş sebzeler arasında incelenen tüm genotoksik PAH'ları içermeleri nedeniyle, patlıcan ve sivri biber ön plana çıkmaktadır. Patlıcanda tespit edilen bu sonucun yüzey alanı ile ilişkili olabileceği düşünülmektedir. Diğer bir deyişle, artan yüzey alanı pişirme kaynağından gelen dumanın gidaya daha fazla akümüle olmasına neden olabilmektedir. Zachara ve ark. (2017) yüzey alanının gıdalarda oluşan PAH seviyesine etki eden önemli bir faktör olduğunu bildirmişlerdir. Ayrıca Rojo ve Toledo (2003), çiğ sebze ve meyvelerde tespit ettikleri farklı seviyelerdeki PAH içeriklerinin yüzey alanı ile ilişkili olabileceğini bildirmişlerdir. Diğer taraftan mevcut araştırmada aynı pişirme süresinde tüm sebze 
örneklerinin yenilebilir düzeyde pişmiş olmasını sağlayabilmek amacıyla patlıcan örnekleri ikiye bölünmüștür. Her ne kadar pişirme işleminden sonra sebzelerin kabukları ayrılmış olsa da, bu durumun da patlıcanda tespit edilen sonuca etki edebileceği düşünülmektedir. Sivri biber örneklerinde gözlenen yüksek PAH seviyesi ise bu sebzenin aynı sicaklık-süre kombinasyonundan daha fazla etkilenmesinden kaynaklanmış olabilir. Yani pişirme esnasında bu sebzedeki sıcaklığın merkez noktaya ulaşma hızı, daha fazla PAH oluşumuna sebep olmuş olabilir. Diğer taraftan McGrath ve ark. (2007) bitki selülozunun yüksek sıcaklıkta gerçekleşen piroliz esnasında bir dizi kimyasal dönüşüm nedeniyle $\mathrm{PAH}$ olușumuna neden olabildiğini bildirmișlerdir. Bu bağlamda Cheng ve ark. (2019) yürüttükleri bir araştırmada, inceledikleri 5 farklı ızgara sebze örneğinde (patates, yeşil biber, frenk soğanı, mantar ve patlıcan) en yüksek toplam PAH miktarının mantara ait olduğunu ve bu durumun mantarın içerdiği yüksek selüloz içeriği ile ilgili olabileceğini rapor etmişlerdir.
Son olarak mevcut araştırmada sadece pişirilmiş ve kabuğu soyulmuş olan yenmeye hazır sebzelerin PAH seviyesi belirlenmiştir. Ancak düşük seviyelerde de olsa çiğ sebzelerin kirli hava, su ve toprak vasitasiyla PAH'larla kontamine olabileceği bildirilmiştir (Paris ve ark., 2018). Bu bağlamda, hammaddelerden kaynaklanacak olası kontaminasyonları azaltmak ve/veya engellemek için çiğ sebze örnekleri pişirilmeden önce yıkama işlemine tabi tutulmuştur. Nitekim, Abou-Arab ve ark. (2014) çiğ sebzelerden kaynaklanabilecek PAH kontaminasyonunun azaltılmasinda veya engellenmesinde yıkama işleminin etkin rol oynadığını bildirmişlerdir.

Tablo 2. Mangalda pişirilmiş sebzelerin $\mathrm{PAH}$ içerikleri (ng/g) (ortalama $\pm \mathrm{SS}$ )

\begin{tabular}{cccccccc}
\hline PAH & Domates & Sarımsak & Soğan & Patlıcan & Sivri biber & Yeşil biber & $\begin{array}{c}\text { Kapya } \\
\text { biber }\end{array}$ \\
\hline BaA & $0.33 \pm 0.30$ & $1.45 \pm 0.02$ & $0.53 \pm 0.07$ & $0.98 \pm 0.90$ & $2.30 \pm 0.15$ & $0.91 \pm 0.88$ & $0.53 \pm 0.01$ \\
Chry & $0.24 \pm 0.01$ & $0.95 \pm 0.09$ & $0.24 \pm 0.05$ & $1.90 \pm 0.65$ & $3.69 \pm 1.13$ & nq- 1.05 & nq \\
BbF & nd & nq & nd & $0.95 \pm 0.46$ & $1.85 \pm 0.77$ & nd & nd \\
BkF & nd & nd & nd & $0.57 \pm 0.32$ & $0.86 \pm 0.36$ & nq & nd \\
BaP & nd & nq & nd & $1.50 \pm 0.67$ & $2.48 \pm 1.14$ & nq & nd \\
DahA & nd & nd & nd & nq- 0.53 & $0.76 \pm 0.35$ & nd & nd \\
BghiP & nd & nq & nd & $0.83 \pm 0.46$ & $1.57 \pm 0.54$ & nq- 0.50 & nd \\
IncdP & nq & $3.18 \pm 1.50$ & nd & nq- 0.51 & $6.52 \pm 1.88$ & nq- -2.32 & nd \\
\hline
\end{tabular}

SS: Standart sapma, nd: <LOD (algılama sınırının altında, nq: LOD $<\ldots \ldots<$ LOQ (kantitatif ölçme sınırının altında)

\section{Temel bileşen analizi}

Mangalda pişirilmiş sebzelerin PAH içeriği açısından değerlendirmelerinin yapılarak aradaki farklıları göstermek için temel bileşen analizi (PCA) uygulanmıştır. Şekil 2'de (A - C), mangalda pişirilmiş sebzelerdeki $\mathrm{PAH}$ içeriklerine ait skor grafiği (score scatter plot), yükleme grafiği (loading scatter plot) ve birleștirilmiş (biplot) temel bileşen analizi skor ve yükleme grafikleri verilmiştir.
Yapılan temel bileşenler analizine göre birinci $(\mathrm{PC} 1=\%$ 90.60) ve ikinci $(\mathrm{PC} 2=\% 8.41)$ bileşenler, toplam varyasyonun \% 99.01'ini açılklamaktadır. Şekil 2A'da görüldüğü gibi, sivri biber, patlıcan, sarımsak ve yeşil biberin PAH içerikleri diğer sebzelerden belirgin bir şekilde ayrılmıştır. Bu durum, sivri biber, patlıcan, sarımsak ve yeşil biberin ihtiva ettiği PAH içeriklerinin diğer sebzelerin PAH içeriklerinden farkl1l1k gösterdiği anlamına gelmektedir. Buna karşın, domates, kapya ve 
soğan, birbirlerine çok yakın bir yerde konumlanmıştır ve bu durum belirtilen sebzelerin PAH içeriklerinin farklılık göstermediği anlamına gelmektedir. Mevcut araştırmada analizi yapılan PAH'ların tamamının birbirleriyle çok önemli pozitif korelasyon gösterdiği görülmektedir (Şekil 2B). PAH'ların miktarları PC1 boyunca artış göstermiștir. $\mathrm{Bu}$ durum, mangalda pișirilmiş sivri biberin karsinojen olan bu bileşikleri diğer sebzelere kıyasla daha yüksek seviyede içerdiği anlamına gelmektedir (Şekil 2C).
A)

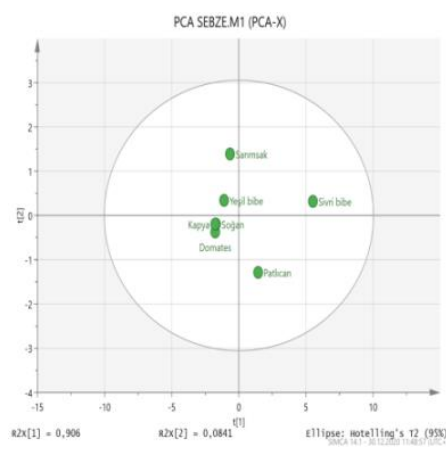

B)

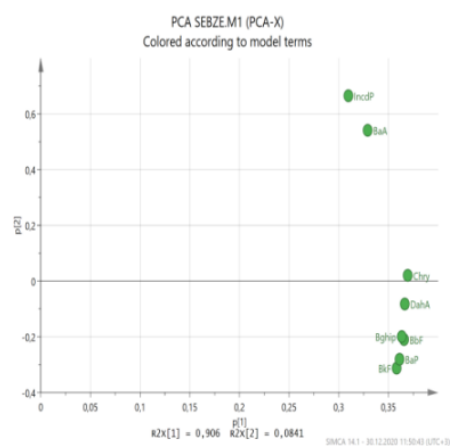

C)

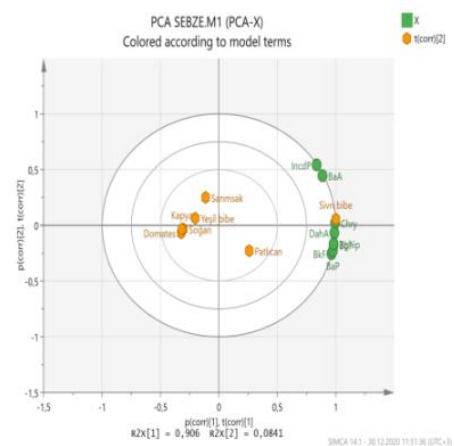

Şekil 2. Mangalda pişirilmiş sebzelerdeki polisiklik aromatik hidrokarbon içeriklerine ait A) skor grafiği (score scatter plot), B) yükleme grafiği (loading scatter plot), C) birleştirilmiş (biplot) temel bileşen analizi skor ve yükleme grafiği

\section{Sonuc}

Araştırma sonuçları mangalda pişirilmiş sebzelerin değişen seviyelerde genotoksik PAH bileşikleri içerdiğini göstermiştir. Domates, kapya biber ve soğanın; sivri biber, patlıcan, sarımsak ve yeşil bibere göre daha az seviyelerde PAH toksikantı içerdiği ve en yüksek toplam PAH içeriğinin sivri bibere ait olduğu tespit edilmiştir. Ayrıca mevcut araştırmada $\mathrm{BaP}$ seviyesi algılama sınırının altında olan örneklerde farklı genotoksik PAH'ların belirlenmesi; gidalardaki PAH riskinin değerlendirilmesinde BaP'nin yanı sıra PAH4 ve PAH8 seviyelerinin de dikkate alınması gerektiği görüşünü destekler niteliktedir.

\section{Kaynaklar}

Abou-Arab, A.A.K., Abou-Donia, M.A.M., ElDars, F.M.S.E., Ali, O.I.M., Hossam, A.G. (2014). Levels of polycyclic aromatic hydrocarbons (PAHS) in some Egyptian vegetables and fruits and their influences by some treatments.
International Journal of Current Microbiology and Applied Sciences 3:277-293.

Akpambang, V.O.E., Purcaro, G., Lajide, L., Amoo, I.A., Conte, L.S., Moret, S. (2015). Polycyclic aromatic hydrocarbons in some Nigerian roasted plant foods. Frontiers in Food \& Nutrition Research 1:1-5.

Alomirah, H., Al-Zenki, S., Al-Hooti, S., Zaghloul, S., Sawaya, W., Ahmed, N., Kannan, K. (2011). Concentrations and dietary exposure to polycyclic aromatic hydrocarbons (PAHs) from grilled and smoked foods. Food Control 22:20282035.

Bogdanovic, T., Pleadin, J., Petricevic, S., Listes, E., Sokolic, D., Markovic, K., Ozogul, F., Simat, V. (2019). The occurrence of polycyclic aromatic hydrocarbons in fish and meat products of Croatia and dietary exposure. Journal of Food Composition and Analysis 75: 49-60. 
Cheng, J., Zhang, X., Ma, Y., Zhao, J., Tang, Z. (2019). Concentrations and distributions of polycyclic aromatic hydrocarbon in vegetables and animal-based foods before and after grilling: Implication for human exposure. Science of the Total Environment 690:965-972.

Comission Regulation (EU). 2011. No: 835/2011 of 19 August 2011 amending Regulation (EC) No: 1881/2006 as regards maximum levels for polycyclic aromatic hydrocarbons in foodstuff.

IARC (International Agency for Research on Cancer), (2010). Some non-heterocyclic polycyclic aromatic hydrocarbons and some related exposures. IARC Monogr. Eval. Carcinog. Risks Hum.

Kazerouni, N., Sinha, R., Hsu, C.H., Greenberg, A., Rothman, N. (2001). Analysis of 200 food items for benzo [a] pyrene and estimation of its intake in an epidemiologic study. Food and Chemical Toxicology 39:423-436.

Lee, Y.N., Lee, S., Kima, J.S., Patra, J.K., Shina, H.S. (2019). Chemical analysis techniques and investigation of polycyclic aromatic hydrocarbons in fruit, vegetables and meats and their products. Food Chemistry 277:156-161.

Lee, J.G., Kim, S.Y., Moon, J.S., Kim, S.H., Kang, D.H., Yoon, H.J. (2016). Effects of grilling procedures on levels of polycyclic aromatic hydrocarbons in grilled meats. Food Chemistry 199:632638.

Li, Y., x Wang, Y., Zou, X., Feng, Z., Yao, Y., Wang, T., Zhang, C. (2019). Occurrence of polycyclic aromatic hydrocarbons (PAHs) in coral reef fish from the South China Sea. Marine Pollution Bulletin 139:339-345.

Martorell, I., Perello, G., Martí-Cid, R., Castell, V., Llobet, J.M., Domingo, J.L. (2010). Polycyclic aromatic hydrocarbons (PAH) in foods and estimated PAH intake by the population of Catalonia, Spain: temporal trend. Environment International 36:424432.

McGrath, T.E., Wooten, J.B., Geoffrey Chan, W., Hajaligol, M.R. (2007). Formation of polycyclic aromatic hydrocarbons from tobacco: The link between low temperature residual solid (char) and PAH formation. Food and Chemical Toxicology 45: 1039-1050.

Oz, E. (2020a). Pişirilmiş et ürünlerinde polisiklik aromatik hidrokarbonların oluşumu ve engelleme yolları. Mühendislik Alanında Akademik Çalışmalar-II, Prof. Dr. Reyhan İrkin (Ed), 179-192, Gece Kitaplığ , Ankara.

Oz, E. (2020b). The impact of fat content and charcoal types on quality and the development of carcinogenic polycyclic aromatic hydrocarbons and heterocyclic aromatic amines formation of barbecued fish. International Journal of Food Science and Technology in press, doi.org/10.1111/ijfs.14748.

Oz, E., Ekiz, E., Savaş, A., Aoudeh, E., EAty, A.M., Oz, F. (2020). Impact of roasting level on fatty acid composition, oil and Polycyclic aromatic hydrocarbon contents of various dried nuts. Turkish Journal of Agriculture and Forestry, In press.

Oz, F., Yüzer, M.O. (2016). The effects of cooking on wire and stone barbecue at different cooking levels on the formation of heterocyclic aromatic amines and polycyclic aromatic hydrocarbons in beef steak. Food Chemistry 203:59-66.

Paris, A., Ledauphin, J., Poinot, P., Gaillard, J.L. (2018). Polycyclic aromatic hydrocarbons in fruits and vegetables: Origin, analysis, and occurrence. Environmental Pollution 234:96-106.

Plaza-Bolanos, P., Garrido Frenich, A., Martínez Vidal, J.L. (2010). Polycyclic aromatic hydrocarbons in food and beverages. Analytical methods and trends. Journal of Chromatography A 1217: 6303-6326.

Rojo Camargo, M.C., Toledo, M.C.F. (2003). Polycyclic aromatic hydrocarbons in Brazilian vegetables and fruits. Food Control 14:49-53.

Rose, M., Holland, J., Dowding, A., Petch, R.S., White, S., Alwyn, Q., et al. (2015). Investigation into the formation of PAHs 
in foods prepared in home to determine the effects of frying, grilling, barbecuing, toasting and roasting. Food and Chemical Toxicology 78:1-9.

Singh, L., Agarwal, T., Simal-Gandara, J. (2020). PAHs, diet and cancer prevention: Cooking process drivenstrategies. Trends in Food Science \& Technology 99: 487-506.

Storelli, M.M., Giacominelli Stuffler, R., Marcotrigiano, G.O. (2003). Polycyclic aromatic hydrocarbons, polychlorinated biphenyls, chlorinated pesticides (DDTs), hexachlorocyclohexane, and hexachlorobenzene residues in smoked seafood. Journal of Food Protection, 66:1095-1099.

Sun, Y., Wu, S., Gong, G. (2019). Trends of research on polycyclic aromatic hydrocarbons in food: A 20-year perspective from 1997 to 2017. Trends in Food Science \& Technology 83:86-98.

Wang, L., Xu, X., Lu, X. (2016). Composition, source and potential risk of polycyclic aromatic hydrocarbons (PAHs) in vegetable soil from the suburbs of Xianyang City, Northwest China: a case study. Environmental Earth Sciences 7556.

Zachara, A., Gałkowska, D., Juszczak, L. (2017). Contamination of smoked meat and fish products from Polish market with polycyclic aromatic hydrocarbons. Food Control 80:45-51. 
Mangalda Pişirilmiş Sebzelerin Polisiklik Aromatik Hidrokarbon İçeriği 